issue 26: Entanglements - Activish and Jechnology

\title{
FCJ-189 Reimagining Work: Entanglements and Frictions around Future of Work Narratives
}

\author{
Laura Forlano \\ Illinois Institute of Technology
}

Megan Halpern

Arizona State University

\begin{abstract}
:
This article explores entanglements and frictions between labour advocates and their relationship to technologies in future of work narratives in the United States. Drawing on literature from science and technology studies and media studies, we argue that there is an opportunity to move beyond discussions of technology as a 'black box' in order to deepen these entanglements and expose the frictions within these discourses. As a means of engaging with the ways in which the future of work is being imagined and opening up discussions around technology, we conducted a one-day participatory design workshop that uses a game in order to reveal the philosophies embedded in labour activism and technology.
\end{abstract}

doi: $10.15307 / f c j .26 .189 .2015$ 


\section{Introduction}

This paper discusses the ways in which labour advocates are enmeshed and entangled in narratives around the role of emerging technologies such as automation, artificial intelligence, and robotics in the future of work. The article draws on literature from science and technology studies and media studies in order to critically analyse narratives about the future of work in the mainstream media. Based on interviews and a design workshop, we argue that participatory design methodologies are one way to engage with and explore the frictions inherent in these future of work narratives in order to find productive ways of bridging the philosophies embedded within labour activism and technology.

Technologies such as crowdsourcing platforms, 'just in time' scheduling software, big data tracking, and robots are at the forefront of discussions around the future of work in the mainstream media. To a large extent, these powerful and far reaching narratives focus on the replacement of workers with technologies in a linear and technologically deterministic manner rather than acknowledging the complex, non-linear, and iterative relationship between activism, social change, and technology. While labour activists continue to advocate for changes that might benefit workers, they are often reacting to the ways in which these debates are framed around emergent technologies. The gaps between the philosophies embedded in labour activism and these technologies are distant. Furthermore, there is little engagement between labour activists and technology activists, who might share some of their values but are positioned differently with respect to their engagement with technology. For example, while labour advocacy groups are canvassing and campaigning to restore and improve the rights of workers, progressive technology activists are advocating for openness, cooperation, and transparency around issues such as network neutrality, intellectual property, and the digital divide.

In order to examine these entanglements and frictions, in July and August 2014, we conducted a three-month project on the future of work. The project included one-hour interviews with 14 labour advocates in Chicago as well as the design of a half-day participatory design workshop. The labour advocates that we interviewed included representatives from organisations working on behalf of youth, immigrants, women, African Americans, Latinos and formerly incarcerated people with a specific focus on the lowest paid and least protected workers including restaurant workers, domestic workers, and healthcare workers. Our interviews revealed that labour activists are both reacting to narratives around the future of work that make revolutionary claims about technological replacement and, on the other hand, engaging with technology such as the Internet and social media in order to mobilise workers around important issues. Thus, somewhat counter intuitively, our interviews demonstrate that, for labour activists 
technology is in some ways still an impenetrable 'black box' while at the same time a site where socio-political values can be enacted for the benefit of activism. Put in other terms, the revolutionary, disruptive, fearful, and dystopian claims of technologists and, somewhat in complicity, economists around technological displacement coexist with more nuanced evolutionary understandings of the ways in which specific tools-in this case, communication technologies-can be developed from a position of greater agency.

The purpose of the workshop was to use design methods in order to explore current and historical relationships between labour and technology as a means of opening up a dialogue on the possibility of imagining and prototyping technologies that could embed philosophies from labour activism. Specifically, we argue that there is an opportunity to identify productive frictions that might allow for the creation of technologies designed around alternative value systems that protect fair and just working conditions. By prototyping such technologies, it is possible to create experiments and demonstrations of how these alternative values might serve to protect and advance the rights of workers. These prototypes could then function as examples that could intervene in future of work narratives in ways that more clearly and accurately represent the philosophies of labour advocates. In addition, a deeper engagement between the philosophies of labour advocacy and technology might help to build technological literacy among labour advocates and social justice literacy among technology activists. This shared literacy could serve to counter claims around technological replacement and, instead, emphasise the need for a reconfiguration of work in collaboration with technologies that are developed, appropriated, and used to create the conditions for a more socially and economically just future. This future could be achieved through the design of our technological systems in tandem with the deliberate effort to shape public policies that reduce inequality, resist discrimination, increase living standards and allow for people to be treated with dignity and respect.

\section{Methodology}

In order to understand the entanglements and frictions between the philosophies embedded in activism and technology, we used several methodologies, including: the analysis of over $\mathbf{2 7 5}$ mainstream media articles; fourteen semi-structured, hour-long qualitative interviews; and, the creation of a participatory design workshop. We conducted interviews with activists from organisations that served diverse communities of workers, ranging from telecommunications workers to domestic workers. While the majority of the activists and organisers were based in Chicago; two were based elsewhere. Eleven of these interviews were conducted prior to the workshop in order to inform its design and three were conducted after the workshop in order to evaluate its results. 
These interviews focused on three concepts related to the work organisers were doing in their respective organisations, and the attitudes they thought they were seeing from their organisations and constituents. The first line of questioning focused on their perceptions of the current and future state of labour practices in the United States, and included questions about challenges and opportunities facing the labour force and their organisations. For the second theme, which was technology, interviewees were asked about their own relationship to technology, the impact they felt it had on their constituents, and work they were to doing to manage that impact. Finally, interviewees were asked about how their organisations planned for the future, and how they and their constituents talked about the future. The purpose of these interviews was to gain a better understanding of pressing issues related to the role of technology in the future of work as well as the kinds of philosophies and values that shaped the work of labour activists in order to inform the design of a workshop. Another reason for the interviews was to reach out to labour activists in order to build relationships with individuals that might be interested in participating in the workshop as well as to get recommendations of additional labour activists and organisations that might want to be interviewed or participate in the workshop. This outreach and interview phase was important to ensure that we had a wide range of groups represented including those that worked on behalf of women, immigrants, youth, formerly incarcerated people, African-Americans, and Latinos in the Chicago area.

Building on the initial interviews and drawing on literature about material deliberation, participatory design, and speculative design, we designed a half-day workshop about technology and the future of work. Public engagement with science and technology often bemoans the lack of what is referred to as upstream engagement in discussions regarding science and technology policy (Hilgartner, 1990). Efforts to create space for voices from publics and their representatives, like citizen juries and consensus conferences, are often esoteric and tedious, and their outcome is often dubious (Joss, 1999; Wynne 2006). While there is a growing movement to develop more approachable methods of deliberation for voicing public concerns about the uses of emergent technologies, it is difficult to gain public interest, or to break through existing narratives. Efforts in anticipatory governance (Barben et al., 2008) aim to anticipate the long-term implications of emerging technologies through methods such as forecasting, public deliberation, scenarios, foresight, and vision assessment. With respect to alternative ways of thinking about deliberation in science and technology studies, Davies et al. (2012) discuss the need for exploring forms of material deliberation. 'It is important to make use of different formats and approaches which highlight not (only) reasoned arguments for particular developments but also the affective connections, materialities, and experiences which structure public interactions...' (2012: 356). While their focus was on the new city, the same principle can be broadly applied to the future of work. In this spirit, we engaged with several design practices and methodologies to develop a kind of material deliberation for labour activists. 
To create an interaction that would provide opportunities for material deliberation, we turned to design methodologies including participatory design and speculative design. We selected participatory design specifically because it was developed in the 1970s and 1980 s in Scandinavia as a means of 'empowering workers and fostering democracy in the workplace' with respect to the development of technology systems through partnerships (Spinuzzi, 2005: 2). According to Spinuzzi:

This avowedly political research aimed to form partnerships with labour unions that would allow workers to determine the shape and scope of new technologies introduced into the workplace. Up to that point, labor unions had little experience with computer technologies and had been forced to accept systems developed by management, systems that represented a sharp break from workers' traditional ways of working; exerted a greater and greater control over increasingly fine details of their work; and automated large swathes of the workflow, putting people out of work (see Ehn, 1990; Zuboff, 1989).

Rather than merely accepting or rejecting technologies that were adopted into the workplace, researchers hoped to provide ways for software developers and workers to develop technologies together, thereby allowing for greater control by workers. Through participatory design, diverse stakeholders can share their ideas, become exposed to the ideas of others, and generate new ideas. Recent design scholarship explores the link between design-whether through objects, exhibits or workshops-and the construction of publics and building of political constituencies and publics around important policy issues (DiSalvo, 2009). Tensions and frictions are particularly relevant to the work of participatory design because according to adversarial design (DiSalvo, 2012), there are many potential benefits to political conflict. Finally, participatory design can serve to raise conceptual questions and form constituencies and publics around important 'matters of concern' (DiSalvo, 2009; DiSalvo, Lodato, Fries, Schechter, and Barnwell, 2011; Latour \& Weibel, 2005).

Few disciplines are equipped to engage with future conditions and concerns in order to raise important questions about alternative possibilities and 'what if' scenarios. Rather than relying on the more deterministic methodology of future forecasting, we turned to speculative design, which emphasises the possibility of multiple alternative futures and uncertainties. Speculative design is also relevant to material deliberation, especially when considering technologies that are not fully developed, or about which there is much concern but little experience. Speculation can give voice to fears and concerns, or it can be a tool for change. Speculative design can create ways of harnessing the drive to think about 'what might be' to help shape 'what will be.' Thus, we drew on speculative 
design methodologies because they allow for a more generative, speculative and futureoriented space of alternative possibilities (Bleecker, 2009; DiSalvo, 2012b; Dunne, 2001). Speculative design allows for issues and ideas to transcend the temporal constraints of the here and now. By moving these methods spatially outside of museums and galleries and into participatory design workshop settings, we are able to use them to transcend both temporal and spatial boundaries.

Approximately twenty-five people including labour activists (8), technology activists (2), designers (9), funders (3) and scholars (3) attended the workshop. Four of the workshop participants were interviewed as part of the project-two before the workshop and two after the workshop. Workshop participants were not paid. One of the authors participated directly in the workshop while the other primarily facilitated and observed. The workshop had two parts. The first part enlisted participants in a board game designed by the authors using critical game theory (Flanagan and Nissenbaum, 2014) and reflective design practices like cultural probes (Gaver, Dunne and Pacenti, 1999). The game was designed for up to four teams of two to four players. Two games were played in tandem with one of the authors participating and observing each game, while a graduate student observed and reported to the authors her impressions of game play. The games each had twelve players total, with three players on each team. Laura Forlano participated on a team, while Megan Halpern observed and answered questions (she was the thirteenth player at the table). The game was an exercise in thinking speculatively about both the past and the future and it represented a timeline that spanned five eras, beginning with ancient Greece and Egypt, and ending in the year 2050. Each space on the board was within an era, and featured a specific point of view. For example, a team might land in "Era 2", on a space labeled "Child factory worker" and might draw a card that asks them to create a list of demands. Or later in the game, they might land on a space that identifies them as a robot worker, and tasks them with sending a postcard from their vacation.

The game allowed workshop participants to explore historical and present technologies, socio-economic conditions, and labour realities in order to open up discussions around the way in which technologies shaped and were shaped by social, economic, political and cultural contexts. It also allowed labour activists to collaborate with scholars, designers and technologists around the creation of counterfactual histories that might allow for alternate relationships, outcomes and possibilities that might benefit workers. However, we were specifically interested in how this engagement might allow for the design of future technologies that might embed the philosophies of labour activists. As a result, the second part of the workshop tasked groups to work together to design an object, prototype, experiment, or platform that drew on the most unexpected or counterintuitive moments during the game play. In order to do this, participants reviewed the ideas that they had come up with as part of imagining counterfactual histories as well as how these ideas 
expressed their values and used them as a basis for the creation of the prototypes. Groups were asked to specify who they were designing for including demographic characteristics such as race, class, gender, economic status, and industry.

Each team from Game A joined with a team from Game B to complete the prototype. Each of the four prototype teams had six members, and each team had forty-five minutes to create their prototype using materials that were in the room. We provided low-fidelity supplies such as cardboard boxes, blue tape, markers, and twine, to encourage the groups to create objects that more closely resembled sketches than polished prototypes. To better understand the impact of the workshop, we paused between activities and at the end of the workshop to ask questions and invite reflections on participants' experiences. These brief focus groups were recorded and analysed along with the interviews that guided the development of the workshop.

\section{Death by Robot}

Mainstream media accounts are full of powerful, revolutionary narratives around the role of emerging technology and the future of work, which position automation, artificial intelligence and robots in opposition to humans in the workforce. The claim is thatfuelled by investment, research and development, Moore's Law (the observation that the number of transistors on integrated circuits doubles every two years), sensors, and the Internet-technologies will replace and/or make many jobs redundant ("Rise of the robots", 2014. According to the proponents of this view, which include many economists and technologists, robots, driverless cars, and drones will 'drive down the value of human labour with astonishing speed' and create 'hordes of citizens of zero economic value' (Davidow and Malone, 2014).

If the first machine age-driven by steam power-resulted in an increase in wages and the standard of living, the 'second machine age' (Brynjolfsson and McAfee, 2014)-driven by big data, computing, and processing-will result in a decrease in wages and the standard of living. These applications of technologies are primarily in three areas: interacting with the physical world, language, and problem solving. One recent book argues that:

the corporate sector is relying on information technology both to simplify and accelerate the processes of business output, and so increase the output of labor, and to deskill labor, 
diminish its role, and so weaken its earning power. The widening gap between the growth of labor's output and its real earnings is the desired outcome of this regime (Head, 2014).

According to a recent study by Frey and Osborne (2013), 47\% of jobs in the United States are believed to be 'at risk' of computerisation. On the other hand, while it is highly likely that the majority of jobs will be reconfigured in some way due to automation and robotics, MIT's David Autor believes that accounts of technological displacement are widely overstated. Currently, it is still difficult for machines to perform tasks that require adaptability, common sense, or creativity (Autor, 2014).

For example, according to many accounts, between 34\% [1] and 44\% [2] of the current active workforce in the United States are contingent workers (a 70\% increase since 2008 according to temporary placement firm Kelly Services), which might include job categories such as freelance, temporary, interns, part-time, self-employed, project based, consultants, contract, and independent workers. Over $40 \%$ of people are currently working or have worked as independent workers. [3] As of 2006, the General Accounting Office estimated that one third of the US workforce or 42 million workers work independently (self-employed, independent contractors, temps, part timers, etc.). Similarly, another study by the Association for Enterprise Opportunity claims that $92 \%$ of all US businesses could be characterized as microbusinesses in that they have fewer than 5 employees, a total of 41.3 million jobs. [4] In February 2014, the Bureau of Labor Statistics reported that 14.4 million Americans were self-employed in areas such as agriculture, which are shrinking, and others such as services, which are growing. Finally, by 2020 , it is believed that roughly $50 \%$ of the private workforce will have spent time as independent workers at some point in their work lives. [5]

In addition, platforms for managing and coordinating contingent work have given rise to new forms of control over workers as well as new job roles. There has been widespread media coverage of so-called sharing economy platforms such as Uber (a taxi service) and Airbnb (an accommodation rental service). However, at the same time, less known forms of work have emerged. These include: TaskRabbits (people that do small tasks and errands such as cleaning and household chores, fixing things and helping with packing and moving as coordinated by online, mobile marketplaces, one of which is called TaskRabbit), Turkers (people that perform work through digital labour platforms such as Amazon Mechanical Turk), cam girls (people that perform live online pornography and sex shows) and gold farmers (people playing video games in order to earn virtual currency, which is exchanged for real money). The Internet and other platforms have also created emergent forms of free and unpaid labour; such as, the work that you do when you check out for yourself when shopping online as well as increasingly at the grocery store, pharmacy, or Apple store. 
According to a recent report on the Future of Artificial Intelligence, Robotics, and the Future of Jobs conducted by the Pew Research Center in August 2014 based on responses from 1,896 experts, it is likely 'robotics and artificial intelligence will permeate wide segments of daily life by 2025 , with huge implications for a range of industries such as healthcare, transport and logistics, customer service, and home maintenance' (2014: 1). The report identifies a number of utopian and dystopian narratives that run through the expert perspectives. Specifically, experts are hopeful that technology will be a net creator of jobs, new types of work will be created, new relationships with work will be more positive, and we will be able to better control our own destiny. On the other hand, experts are concerned that automation will disrupt white-collar work, that many people will become unemployed or underemployed in lower wage jobs, and that our educational system is failing to prepare us for the future.

While emerging technologies will likely disrupt and reconfigure jobs, employment and the future of work, they are unlikely to replace humans altogether. At the same time, these displacements may alter the quantity and quality of work as well as the type of work we will do in the future with the creation of completely new job categories. Futhermore these displacements may be felt more severely in some sectors, jobs and populations than in others. So, why have narratives around the replacement of humans by robots come to dominate the mainstream media coverage around technology and the future of work? Who is framing the debate in this way and who is benefitting from this particular framing? How are the views of labour advocates being included or excluded from these narratives? Where are there entanglements and frictions between technologies, as they are being represented, and the philosophies of labour advocacy? How might design be a way to open up these debates and reveal possibilities for productive engagement between activism and technology? Accounts by labour advocates as well as scholarly understandings around the role of technology and the transformation of work may allow us to better understand these entanglements and frictions. For example, recent scholarship has also considered the role of digital labour (Scholz, 2012), free labour (Terranova, 2000), unpaid labour (Andrejevic, 2012), immaterial labour (Lazzarato, 1996), and affective labour (Hardt, 1999).

\section{Frictions and Entanglements between Technologies and Labour Activists}

This paper seeks to understand-through a lens of science and technology studies and media studies - the entanglements that arise due to frictions between the philosophies embedded within technologies and the philosophies embedded within labour activism as 
evidenced by the discourses and narratives around the future of work. According to the Oxford Dictionaries, there are two distinct meanings of the term friction both of which are related to the discussion about activism and technology. First, "the resistance that one surface or object encounters when moving over another'; and, second 'conflict or animosity caused by a clash of wills, temperaments, or opinions.' [6] In particular, with respect to the role of technology and its relationship to work and labour activism, the references to both resistance and conflict are relevant.

In particular, we discuss the ways in which labour activists might engage more deeply with technologies, necessarily requiring the negotiation of acceptance, compromise, or submission (Tsing, 2005). According to Tsing, 'Cultural diversity brings a creative friction to global connections...These zones of cultural friction are transient; they arise out of encounters and interactions...[they are] the awkward, unstable and creative qualities of interconnection across difference' (2005: 4). Tsing proposes that friction is a metaphor that captures the diverse and conflicting zones of awkward engagement that make up our contemporary world. We might also consider these frictions with respect to notions of dissensus (Mouffe, 2003), conflicts (Hillgren, Seravalli, and Emilson, 2011) and agonism (DiSalvo, 2012). We believe that this friction is both disruptive for labour advocates as well as productive for the development of technologies framed around alternative future possibilities, which embed notions of fairness, justice, and equality. By examining these frictions with respect to narratives around the future of work, it is possible to critically analyse engagements between labour advocates and technologies.

Mainstream media accounts emphasise a certain revolutionary and technological determinism that is nameless, faceless, and without context. The future is represented as either a utopia of leisure in which humans no longer need to work or a dystopia of competition in which humans must compete with machines in order to survive. In this framing, technology is a 'black box'. It is a disembodied, objective and neutral tool that is used within a capitalist system to control, manage and replace workers. As such, there is little that humans, let alone labour advocates, can do to prevent its adoption and use. With this framing, it is only natural that labour advocates voice fears about technological unemployment, job scarcity and declining growth rates, and the implications for the middle class and wages in the United States.

Yet, in some ways, for labour organisers technology is simultaneously a 'black box,' which is impenetrable, and a tool for change and activism. For example, Edward, who ran a group that advocated for day labourers and domestic workers, did not have concerns about automation, whereas Alan, who worked in telecommunications, had already seen many jobs lost in the wake of simplified communications technology, but saw technology as a 
tool for fulfilling the need to retrain workers to help them rejoin the workforce. This dual nature of philosophies embedded within technology seems to further complicate existing social theories, which consider technology either as a 'black box' with complete agency over the social or as a social construction that coevolves with the social. However, more recent scholarship around socio-materiality (Orlikowski, 2007), digital materiality (Dourish and Mazmanian, 2011; Leonardi, 2010; Robles and Wiberg, 2011), object-oriented ontology (Bogost, 2012) and new materialism (Barad, 2003; Parikka, 2012) has attempted to account for this agency of artifacts, objects and technologies while at the same time explaining their socially constructed nature in what is becoming understood as a turn back towards materialism.

This approach to materialism can be observed not only in mainstream media accounts around technology but it is also present in our interviews with labour advocates. For example, according to one union organiser:

DARREN: I don't think that there is an example in human history of technology being rejected because of the disruption that it creates, ... At the end of the day, technology wins in military history, in labor history. ... Is Moore's Law an equivalent of the transition from steam to electricity or is it a permanent thing? You get completely different alternative futures depending on what you believe. ... If you believe that Moore's Law will settle down then you will have labor shortages, declining birthrates, not enough people for the work that needs to be done and fewer younger people than there are old people. ... If Moore's Law continues, then you have technological unemployment for the first time in human history ... not short-term, not disruptions that produce migrations and resettlements to different sectors or different geographies. ... How do you solve for human prosperity when there is a scarcity of work for the first time? There are the two very different futures. In one, there are 7 billion people competing for 2 billion jobs. ... There are signs of both futures out there.

In contrast to this view, an alternative framing of the philosophies embedded within technologies might be one of evolutionary change in which technologies are socially constructed and mutually constituted (Bijker and Law, 1994; Pinch and Bijker, 1984), embedded in socio-economic and socio-technical systems (Star, 1999), reconfigurations of invisible labour (Latour, 1992) and imbued with society's values (Friedman and Nissenbaum, 1996; Nissenbaum, 2001). For example, in order to provide an alternative framing of technology, it is important to challenge the notion that Moore's Law is a scientific law. Rather, it is an observation that became embedded into corporate culture as an engineering goal or metric for success in order to sustain sales and profits (Dourish and 
Bell, 2011). This helps to open up a discussion around the ways in which particular values and even temporalities become embedded into socio-technological systems that shape work and the economy.

Suchman has discussed the ways in which Silicon Valley projects, constructs and claims certain kinds of futures, while, at the same time, deliberately excluding and ignoring other futures, people and geographies (2011). While 18-month cycles of planned obsolescence (Fitzpatrick, 2011; McDonough and Braungart, 2002) shape the revolutionary discourses around which corporate technologies are developed, marketed and sold, the temporalities and futures as experienced by labour advocates are quite different. Rather than taking the lead to frame issues and discourses about the future of work, labour advocates are often responding to the actions of business and government. Especially when it comes to discussions around technological change, labour advocates acknowledge that they are often reactionary in nature since they have sometimes failed to understand the kinds of technological changes that will likely transform the future of work.

For the most part, the work of labour advocates (as well as other forms of activism) is demarcated in relatively short increments, from 3-6 months to campaign cycles to annual funding deadlines. While different organisations confront different timelines, the everyday pressures on their plans and schedules, make it difficult to think beyond immediate goals and constraints. At the most expansive, 'the future' was characterised as a 5-year strategic plan. For example, one immigrant rights advocate, Jonathan, characterised three specific time horizons in which his work was divided: near term (current policy decisions being made by the administration), long term (within the next 5-years and into the second term of a new President) and very long range (large structural changes that have been continuing since the 1970s). However, according to David, an advocate for healthcare workers, while there are immediate and longer-term issues that shape the nature of the work, overall, time is a continual process that is changing and fluid in relation to developments in healthcare. This conflict between the philosophies of time that are embedded in technologies and those embedded in labour activism offers one site of potential engagement, which we will take up in the next section of the paper. In fact, the very notion of chronological time (and, therefore, ideas about the future) is currently being challenged by recent discussions in queer feminist scholarship (Barad, 2007).

With respect to the entanglements between human and non-human actors and the delegation of competencies (Latour, 1992), in a recent book review, Irani points out that the overemphasis on artificial intelligence and robotics misses two important points: first, that these technologies are actually made possible by huge amounts of invisible labour and, second, that 'Automation doesn't replace labour. It displaces it,' (2015: 2). Yet, according 
to Joseph Thomas Phelan, a communications strategist within the emergent worker justice movement:

the 'the robots are coming' argument has some very amazing and compelling stories that tie neatly into popular culture narratives about both the promise and peril of the rise of the robots. As an organiser l've learned that it is these small stories and meta-narratives wired into emotions and values that drive people's actions, regrettably not facts. [7]

Furthermore, these narratives about technology reify, and even degrade, existing social and economic realities rather than signalling opportunities to shift priorities and values. Technology has affordances (Gibson, 1977; Norman, 1990) and limitations that interact with and shape social systems; however, the ways in which we design, appropriate, and use technologies occurs in dialogue with socio-economic systems. As Zeynep Tufekci argues in light of narratives around the need for caregiver robots that will mind our children and accompany us through old age, 'This is not just an inhuman policy perspective, it's economically destructive and rests on accepting current economic policies and realities as if they were immutable' (2014: 1). Domestic workers and home care workers are some of the lowest paid and most poorly treated contingent workers in the United States (Tufekci, 2014) because they have few legal protections. Tufekci argues that this kind of emotional labour which is to a large extent performed by women and immigrants, in particular, is undervalued and therefore under paid and (sometimes) unpaid.

For the labour advocates we interviewed emerging technologies are both understood as a 'black box' and, at the same time as tools, for activism and campaigning. One the one hand, technologies such as artificial intelligence and robots are too abstract and, as a result, it is not surprising that labour advocates adopt a more fearful perspective when compared to their attitudes towards other kinds of technologies. At the same time, communication technology such as social media and the Internet were valued as having great potential for labour advocacy groups. Some groups do not think about technology very much, and some not at all, within the context of their work.

There are several specific entanglements and frictions between the philosophies embedded within labour activism and the philosophies embedded within technology that we have identified: participation and control, skills and literacy, and access and appropriation. With respect to discourses around technology and media related to participation and control, in recent years, there has been considerable scholarship on topics including civic engagement (DiSalvo, 2009; Foth, Forlano, Gibbs, and Satchell, 
2011; Gordon and Koo, 2008), participatory culture and participatory media (Bruns and Burgess, 2011; Burgess, Foth, and Klaebe, 2006; Burgess and Green, 2013; Rheingold, 2008) and open source software and peer production (Benkler, 2006). One way in which these discussions play out around future of work narratives is with respect to 'just in time' scheduling technologies. For example, according to a position paper by Gleason and Lambert:

New protections and greater voice for workers are needed to realize the potential that workforce technologies have for restoring a fair workweek for millions of hourly workers. When technology is something solely controlled by management to increase profit, in a context where workers are almost all unorganised, a future of work where most workers are pushed even further to the margins of society is all but guaranteed (2014: 5).

Since the adoption and use of these technologies are controlled by management rather than by workers-and/or through negotiation between management and workers-these technologies are imbued with values associated with increasing profit by efficiently allocating work hours. In this case, there is friction between the values embedded in 'just in time' scheduling platforms and the values that labour activists are working towards to guarantee a fair workweek. These two sets of values need not necessarily be in conflict but they reflect deeper inequalities in the economy with respect to the balance of power between management and workers. In particular, the erosion of the power of unions and the lack of adequate new forms of organisation that might support the rights of workers is apparent.

Another friction between technologies and labour activists surrounds the issue of access and appropriation of technology such as broadband; an issue that has been discussed by scholars with respect to the digital divide and digital inequality (DiMaggio, Hargittai, Celeste, and Shafer, 2004; DiMaggio, Hargittai, Neuman, and Robinson, 2001; Forlano and Powell, 2011; Hargittai, 2007). According to Karl, a labour advocate in the education sector, social media such as Twitter has been used effectively to organise educators and unions. One particularly successful campaign \#thewholestory, which used a hashtag aimed to correct a series of Chicago Tribune stories about teacher certification, garnered 5 million impressions on Twitter. Yet, while middle class parents are technology-savvy, have broadband access and are engaged in their schools, the majority of people that send their kids to Chicago public schools do not have access to broadband and 160 schools do not even have libraries. Karl says, 'You can push these apps as a boon to democracy but if people don't have access it is not really doing any good.' This illustrates the ways in which labour activists acknowledge how communication technology can open up avenues for 
activism and social change if people have access to it. But it is not enough to have mere access to technology; it is also necessary to have the technological literacy and skills in order to use it effectively and creatively.

This point about technological literacy and skills is well illustrated by a position paper by the Design Studio for Social Intervention, a social justice non-profit organisation in Boston that writes:

what youth of color need is not new technologies (they have them), but equal opportunity to build on these technologies, to deploy their own creativity, and to amplify their entrepreneurial spirit and hustle. Youth of color are ready and willing to be more than consumers: to learn code, use 3-D printers and digital fabrication, "hack" new styles into clothes, create new uses for social media, etc. They need opportunities that build on their skills, knowledge and existing social practices-respecting the ingenuity of current hustles, building on the skills they've taught themselves in regards to entrepreneurship, technology, and networking (Lobenstine and Bailey, 2014: 6).

The organisation points out that many of the social practices that have existed in communities of colour for many years (and been criticised and condemned by mainstream society) are now heralded as boons of the sharing economy. For example, apartment sharing that was once considered illegal has now been reinvented by Airbnb as a symbol of the so-called sharing economy. In this case, social justice organisations such as the Design Studio for Social Intervention are entangled in advancing some of the same philosophies that are deeply embedded into Silicon Valley engineering culture and the United States government's push to train more and more people in Science Technology Engineering and Math (STEM) fields (and simultaneously cut funding to the humanities, the social sciences and the arts). There is considerable debate over whether there is any inherent value in learning to code, design 3-D printed objects, advance disruptive innovation or foster an entrepreneurial spirit (Lepore, 2014; McPherson, 2008). Will learning to code allow communities of colour to obtain higher paying jobs or will it serve to suppress wages due to a larger supply of qualified applicants? It is difficult to argue that youth of colour should be denied the same kinds of technological literacy, skills, and knowledge that have become mainstream among other socio-economic groups.

Overall, our interviews with labour activists as well as recent publications by social justice advocacy organisations highlight the ways in which their own narratives around the role of technology and the future of work are entangled with and, at times, in friction and 
conflict with the philosophies and values embedded in technologies vis a vis the future of work. By understanding these entanglements and frictions more deeply, it is possible to identify opportunities to design technological systems that can negotiate between these multiple philosophies and values. One example of this kind of negotiation with respect to crowdsourcing platforms and digital labour marketplaces is discussed here:

How can Turkers move past these disputes and act together on matters that they do agree on? Just as paid crowdsourcing has reconfigured the dynamics of work, introducing a new form of labor that relies on temporary labor relations and short term tasks, it seems that the distributed nature of the workforce may also be transforming the requirements of labor activism. What would the equivalent of a labor union look like online? (Salehi, Irani, Khatib, and Bernstein, 2014: 3)

Turkopticon and Dynamo are two specific platforms that can be understood as design interventions that embed alternative sets of values and possibilities around labour activism (Irani and Silberman, 2013; Irani and Silberman, 2014; Salehi et al., 2014). In a similar vein, our interviews and background research on the role of technology in the future of work led us to explore the use of participatory design and speculative design in order to find ways of opening up discussions, challenging the depictions of the role of technology in the future of work as portrayed by mainstream media representations, negotiating between multiple philosophies embedded within technologies and labour activism, and developing productive frictions that might lead to ideas for prototypes of technologies that might embed ideals of social justice.

\section{Reimagining Work}

Our participatory and speculative design workshop allowed us to engage in discussions around technology and labour including their historical relationships, the values and philosophies embedded in particular reconfigurations and the ways in which alternate possible futures could be imagined and prototyped. Through the workshop, we sought to position the future as a temporal socio-technical space that was actively becoming and being made by labour advocates with their values and philosophies in mind rather than merely acting upon them as a linear, disruptive and revolutionary force. We aimed to further open up the 'black box' of technology in to a space of engagement, participation and access by labour advocates, while, at the same time, understanding the limitations and constraints of this approach. Specifically, even if technologies are designed 
around particular activist values and technologies, it is difficult to control their adoption, appropriation and use. This is particularly true in the case of labour activism because, as pointed out earlier, to a great extent, workers do not have control over the technologies that they use and those that are used to manage them since many no longer participate in formal labour organisations.

In this section, we will draw examples from the workshop to illustrate the ways in which we engaged with narratives and discourses around the future and technology as well as what we learned about the entanglements and frictions between the philosophies embedded in technology and those in labour activism. With respect to the temporal boundaries of the workshop, the game that we designed stretched from 3000 years in the past to 30 years into the future. After experiencing the expanded time horizon in the game to understand labour organising throughout history including, for example, the histories of slave revolts in Ancient Egypt, Jonathan, a labour advocate, said, 'It is possible to ask what does a collective at the workplace look like 50 years from now...that kind of imaginative exercise allows people to see new possibilities.'

David, the healthcare labour advocate said, 'There is real value in thinking things through... seeing the progression and the interaction historically and concretely in a way. Often, [we] don't do the work of sitting down and examining what has occurred historically.' As part of the game, we asked participants in the workshop to create campaigns, artifacts, uniforms, schedules and technologies as part of building counterfactual histories. These histories were a way of imagining the past that opened up potential conversations about speculating about the future. For example, Penny, a participant from the nonprofit community, suggested that the work done through the game was empowering.

PENNY: There's something kind of empowering about seeing that throughout all these ages, it's a process of workers that are responding to the conditions they find themselves in and even in our little team of two or three people, that in some small way were creatively trying to respond to a challenge of our work situation that was in front of us.

Similarly, the speculative aspect of creating alternative histories inspired another workshop participant:

ALAN: I really liked the term counterfactual. It was humorous and fun but also helps break open some creative energy. And there are counter histories so it's 
sort of thinking about what history are we paying attention to. Are we looking at the social history of conditions of work? Are we looking at industrial history and new forms of production and celebration of technology? So I think maybe it's about just being critical about what are we looking at as history, what constitutes history, and that's what's perhaps helpful. Are we taking inspiration from this history or from this history when we're thinking about current conditions?

The first era represented on the game board was Ancient Greece and Egypt. Players were asked to speculate about what it may have been like to build the pyramids, or to work as a slave in someone's home. Participants agreed that thinking so far into the past was more difficult to them than thinking about the other more recent and familiar eras represented, including the future.

There was a connection between the ability to imagine alternatives to historical narratives and the ability to imagine or recall existing narratives. For example, not knowing the power structures or labour practices of the Egyptians made it difficult for the participants to imagine what a list of demands would look like in Ancient Egypt. Moreover, as one participant pointed out, knowledge of history was not always helpful in opening up new ideas for the past or present. Repeating themes of oppression throughout the history of labour, combined with the hope for change that forms the basis of the work labour advocates do, made it difficult to decide whether to represent a perceived reality or an optimistic future. Threading this difficult needle helped maintain the nuanced balance between the dystopian and utopian extremes that creep into most discussions of the future including the mainstream media representations around the role of technology and the future of work.

JARED: I thought it was sort of hard to balance ideas that were imaginative or optimistic with ones that were pragmatic, especially [unintelligible] because we know what the constraints were. Yeah, trying to think of solutions that are workable vs. ones that are fun.

Though these speculations about the past were challenging, they were successful in illustrating the values and philosophies held by labour advocates through the creation of interventions during the game play. During the prototyping session participants were able to experience the ways in which hands-on material engagement allowed the group's ideas to move forward. For example, Penny noted that she had an expectation that discussions yield insight and decision-making, and that creating something is a result of meticulous planning and discussion. However, during the prototyping activity, she found that her 
group's conversation did not move forward until they began to make their prototype. It was the act of making that enabled them to make decisions and move forward.

PENNY: I was struck by the last exercise, when we started off in our group just talking. We were talking around each other, until you actually came in and intervened and said you must get up and do something. It wasn't until we actually started physically moving that we-we were developing our idea as we were just putting stuff together, and for a linear thinker it is just like how did that happen? We're used to brainstorming...you have to battle out the ideas before you get to any kind of action, and this was actually, you know, doing a physicality that actually helped me think through a problem.

While Penny focused on her surprise to find that decisions were made through actions rather than deliberation. Aiden, a software developer, articulated a similar observation about his expectations and his experience of the prototyping activity, but from a different perspective. He found that the activity provided greater understanding of the complex set of issues surrounding labour and technology, rather than a plan for a product.

\begin{abstract}
AIDEN: The product that came out of this was more of a really good understanding of some of the dimensions of the problem space, more so than actionable prototypes for interventions- which I think is counterintuitive when you hear that you're going to be prototyping in teams. I think a lot, as a software developer, like hackathons are very popular collaborative event. But those are often times too focused on making some kind of product, and then those are seen as the outcome rather than by making something you get an understanding of the dimensions.
\end{abstract}

While Penny's prior experience and her field prompted her to think about process, Aiden's work in software was more product-focused. Despite the focus on process or product, it seems that the aims and outcomes of the activities were inverted with the norm. The convention, for both Penny and Aiden, was that discussion developed thoughts and ideas, and design developed products. They both articulated surprise at the ways in which the design work prompted and enhanced, or shaped, thinking. This transformation toward making as a way of knowing particularly helped Penny's group, as well as Halpern's group, to break out of circular conversations and move toward consensus.

Overall, through the participatory and speculative design workshop, participants were able 
to engage with a reimagining of the relationship between labour and technology based on the values held by labour advocates. The workshop served as a forum in which to imagine the future, breaking out of the day-to-day temporal constraints of policy advocacy as well as challenging some of the established ways of thinking about technology which are well represented in mainstream media debates. Through rigorous discussion both during the game and the prototyping activity a complex and nuanced understanding emerged of how technology and its philosophies are embedded in socio-technical systems. The workshop left us with a number of questions about the entanglements and frictions between the philosophies of labour activists and technologies as well as about possible future directions for our methodology.

\section{Future Directions}

While the participatory and speculative design workshop activities including the game and prototyping exercises were useful in opening up conversations and challenging dominant narratives about technology and the future as well as expressing the values and philosophies of labour activists, we found that there were specific ways in which our goals could have been more explicit. For example, during the wrap up discussion following the workshop, David mentioned that the workshop could have been more explicitly connected to social justice concerns and the conditions of low-income workers. While we expected the labour activists to represent their own positions and constituencies during the game and prototyping activities, it is possible that due to the mixed group of workshop participants, the team members did not share the same values and commitments. Rather than allowing the game and prototyping activities to be relatively open-ended, we might have given the teams more specific constraints and direction. For example, in the game, rather than 'design a schedule' or 'design a logo' for a fisherman in Ancient Greece, each of the game cards could have been directly tied to achieving certain improvements in the lives of workers. In this case, the prompt would need to state more clearly 'design a schedule that offers greater leisure time' or 'design a logo that shows the empowerment of workers.'

Furthermore, our follow up interviews after the workshop suggest that there is great potential to create a version of participatory and speculative design workshop specifically for workers (rather than their labour advocacy intermediaries). This is because workers may have direct experiences with the ways in which technology is shaping their day-to-day work as well as the ways that they are using it for their jobs as well as for social support. However, at the same time, with low-wage jobs, it is extremely unlikely that workers are being consulted when decisions about which technologies to adopt are being made by 
specific employers. Specifically, the labour advocates that we spoke with were supportive of the possibility of using design methods for the purpose of building a greater sense of agency in ongoing socio-technical narratives around work as well as for translating individual experiences of work to broader structural inequalities that are shared by groups of workers. The activists indicated their constituents might find value and agency from the workshop, suggesting it supported meaningful material deliberation.

In keeping with the methodological traditions of participatory design in shaping technologies to benefit workers by incorporating their tacit knowledge, we believe that participatory and speculative design methods offer one way of potentially engaging in discussions around the role of technology in future of work narratives as well as surfacing the entanglements and frictions between labour activists and technologies. However, while participatory design focused primarily on organised groups of workers at the same organisation, we believe that there is value in extending it to distributed and unorganised workers that may share similar experiences but not yet be affiliated with one another in order to build constituencies.

In particular, a design intervention of this kind may be important and useful in situations in which workers are most isolated from one another, such as domestic workers and homecare workers. These individuals often do not identify as "workers" since they do not perform their jobs at a traditional workplace. Domestic workers and homecare workers are some of the lowest paid workers and due to their contingent nature have few protections in the United States under the law. Furthermore, a range of digital technologies such as mobile applications, keycard access, 'nanny cams' and other mechanisms are used to track them at work. As a result, there is potential not only to employ design methods as one means of bringing workers together but also engaging with technology activists to create alternative applications and platforms that could benefit domestic workers and homecare workers directly.

Furthermore, it is critical that future projects enable labour advocates to strengthen their participation with, access to, and literacy about technology through meaningful material engagements. This would allow for a deeper negotiation between the philosophies embedded in labour activism and those present within technologies. This deeper engagement could be mobilised productively to create demonstrations, experiments, and prototypes that could intervene in discourses around the role of technology in the future of work. It could also reveal additional sites of conflict between the philosophies of labour activists and the ways in which technologies are positioned vis a vis the future of work. It is only through this kind of intimacy and entanglement between labour advocates and emerging technologies that it is possible to shift the embedded values in the discourses 
that are continuing to powerfully shape the terms of the debate and the decisions that business leaders and government officials are making when they consider the role of technology in the future of work.

\section{Biographical Note}

Laura Forlano is an Assistant Professor at the Institute of Design at Illinois Institute of Technology. Her research is focused on the intersection between emerging technologies, material practices and the future of cities with a specific focus on emergent forms of organising and urbanism.

Megan Halpern is a Postdoctoral Associate at Arizona State University. Her research interests include collaboration in art, science, and design; human computer interaction design; and public engagement with science. Her recent work has focused on the relationship between experts and audiences in a variety of contexts in both the performing arts and sciences.

\section{Notes}

[1] See https://www.freelancersunion.org

[2] See http://www.kellyservices.com/Global/The_Talent_Project_iPad_App/

[3] See http://www.mbopartners.com/state-of-independence

[4] See http://www.microenterpriseworks.org

[5] See http://www.mbopartners.com/state-of-independence 
[6] See http://www.oxforddictionaries.com/us/definition/american_english/friction

[7] E-mail correspondence with Joseph Thomas Phelan on February 25, 2015.

\section{References}

Andrejevic, Mark. 'Exploitation in the Data Mine', in Christian Fuchs, Kees Boersma, Anders Albrechtslund and Marisol Sandoval (eds). Internet and Surveillance: The Challenges of Web 2.0 and Social Media (London: Routledge, 2012), 71-88.

Autor, David. 'Polanyi's Paradox and the Shape of Employment Growth'. Paper presented at the Federal Reserve Bank of Kansas City, Kansas City (2014).

Barad, Karen. 'Posthumanist Performativity: Toward an Understanding of How Matter Comes to Matter', Signs 28.3 (2003): 801-831.

Barad, Karen. Meeting the Universe Halfway: Quantum Physics and the Entanglement of Matter and Meaning (Durham, NC: Duke University Press, 2007).

Barben, Daniel, Erik Fisher, Cynthia Selin, and David H. Guston. 'Anticipatory Governance of Nanotechnology: Foresight, Engagement, and Integration', in Edward J. Hackett, Olga Amsterdamska Michael Lynch and Judy Wajcman (eds). The Handbook of Science and Technology Studies 3. (Cambridge, Mass: MIT Press, 2007), 979-1000.

Benkler, Yochai. The Wealth of Networks: How Social Production Transforms Markets and Freedom (New Haven, CT: Yale University Press 2006).

Bijker, Wiebe. E., and John Law (eds). Shaping Technology / Building Society: Studies in Sociotechnical Change (Cambridge, Mass: MIT Press, 1994).

Bogost, lan. Alien Phenomenology, or What It's Like to be a Thing. (Minneapolis: University of Minnesota Press, 2012).

Brynjolfsson, Erik and Andrew McAfee. The Second Machine Age: Work, Progress, and Prosperity in a Time of Brilliant Technologies (WW Norton and Company, 2014).

Bruns, Axel and Jean E. Burgess. 'The Use of Twitter Hashtags in the Formation of Ad Hoc Publics'. In 6th European Consortium for Political Research General Conference, 25 - 27 August 2011, University of Iceland, Reykjavik (2011).

Burgess, Jean, Marcus Foth and Helen G. Klaebe. 'Everyday Creativity as Civic Engagement: A Cultural Citizenship View of New Media', in Communications Policy \& Research Forum, Sep 25-26, Sydney (2006).

Burgess, Jean, and Joshua Green. YouTube: Online Video and Participatory Culture (John 
Wiley and Sons, 2013).

Davidow, William H. and Michael S. Malone. 'What Happens to Society When Robots Replace Workers'? Harvard Business Review 10 December (2014).

Davies, Sarah. R., Cynthia Selin, Gretchen Gano, and Ângela. G. Pereira. 'Citizen Engagement and Urban Change: Three Case Studies of Material Deliberation', Cities 29.6 (2012): 351-357.

DiMaggio, Paul, Eszter Hargittai, Coral Celeste, and Steven Shafer. 'Digital Inequality: From Unequal Access to Differentiated Use', Social Inequality (2004): 355-400.

DiMaggio, Paul, Eszter Hargittai, W. Russell Neuman, and John P. Robinson. 'Social Implications of the Internet', Annual Review of Sociology (2001): 307-336.

DiSalvo, Carl. 'Design and the Construction of Publics', Design Issues 25.1 (2009): 48-63.

DiSalvo, Carl. Adversarial Design. (Cambridge, Mass: MIT Press, 2012).

DiSalvo, Carl, Thomas Lodato, Laura Fries, Beth Schechter and Thomas Barnwell. 'The Collective Articulation of Issues as Design Practice', CoDesign 7.3-4 (2011): 185-197.

Dourish, Paul, and Genevieve Bell. Divining a Digital Future: Mess and Mythology in Ubiquitous Computing (Cambridge, Mass: MIT Press, 2011).

Dourish, Paul, and Melissa Mazmanian. 'Media as Material: Information Representations as Material Foundations for Organisational Practice'. Paper presented at the Third International Symposium on Process Organisational Studies, Corfu, Greece (2011).

Fitzpatrick, Kathleen. Planned Obsolescence: Publishing, Technology, and the Future of the Academy (New York: NYU Press, 2011).

Flanagan, Mary, and Helen Nissenbaum. Values at Play in Digital Games (Cambridge, Mass: MIT Press, 2014).

Forlano, Laura. 'Anytime? Anywhere?: Reframing Debates Around Community and Municipal Wireless Networking', Journal of Community Informatics 4.1 (2008).

Forlano, Laura and Alison Powell. From the Digital Divide to Digital Excellence: Global Best Practices for Municipal and Community Wireless Networks (Washington, DC: New America Foundation, 2011).

Foth, Marcus, Laura Forlano, Martin Gibbs, and Christine Satchell. From Social Butterfly to Engaged Citizen: Urban Informatics, Social Media, Ubiquitous Computing, and Mobile Technology to Support Citizen Engagement (Cambridge, Mass: MIT Press, 2011).

Frey, Carl Benedikt and Michael A. Osborne. 'The Future of Employment: How Susceptible are Jobs to Computerisation'? Paper presented at the Machines and Employment Workshop, Oxford, England (2013).

Friedman, Batya, and Helen Nissenbaum. 'Bias in computer systems', ACM Transactions on Information Systems (TOIS) 14.3 (1996): 330-347. 
Gaver, Bill, Tony Dunne and Elena Pacenti. 'Design: Cultural Probes', Interactions 6.1 (1999): 21-29.

Gibson, J.J. 'The Theory of Affordances', in Robert Shaw and John D. Bransford (eds). Perceiving, Acting and Knowing: Toward an Ecological Psychology (New York: Wiley, 1977), 67-82.

Gleason, Carrie and Susan Lambert. 'Uncertainty by the Hour', Future of Work Project (Open Society Foundations, 2014).

Gordon, Eric, and Gene Koo. 'Placeworlds: Using Virtual Worlds to Foster Civic Engagement', Space and Culture 11.3 (2008): 204-221.

Hardt, Michael. 'Affective Labor', Boundary 2 (1999): 89-100.

Hargittai, Eszter. 'Whose space? Differences Among Users and Non Users of Social Network Sites', Journal of Computer Mediated Communication 13.1 (2007): 276-297.

Head, Simon. Mindless: Why Smarter Machines are Making Dumber Humans (Basic Books, 2014).

Hilgartner, Stephen. 'The Dominant View of Popularization: Conceptual Problems, Political Uses', Social Studies of Science 20.3 (1990): 519-539.

Hillgren, Per-Anders, Anna Seravalli and Anders Emilson. 'Prototyping and Infrastructuring in Design for Social Innovation', CoDesign 7.3-4 (2011): 169-183.

Irani, Lilly. 'Justice for "Data Janitors", Public Books, 15 January (2015), http://www.publicbooks.org/nonfiction/justice-for-data-janitors

Irani, Lilly and M. Six Silberman. Turkopticon: Interrupting Worker Invisibility in Amazon Mechanical Turk. Paper presented at the Proceedings of the SIGCHI Conference on Human Factors in Computing Systems (2013).

Irani, Lilly and M. Six Silberman. 'From Critical Design to Critical Infrastructure: Lessons from Turkopticon', Interactions 21.4 (2014): 32-35.

Joss, Simon. 'Introduction: Public Participation in Science and Technology Policy and Decision Making-Ephemeral Phenomenon or Lasting Change'? Science and Public Policy 26 (1999): 290-293.

Latour, Bruno. 'Where are the Missing Masses? A Sociology of Few Mundane Objects', in Wiebe E. Bijker and John Law (eds). Shaping Technology/Building Society. Studies in Sociotechnical Change (Cambridge, Mass: MIT Press, 1992), 151-180.

Latour, Bruno. 'On Actor-Network Theory: A Few Clarifications', Soziale Welt (1996): 369_ 381.

Latour, Bruno. Reassembling the Social: An Introduction to Actor-Network-Theory (Oxford: Oxford University Press, 2005). 
Law, John. After Method: Mess in Social Science Research (London: Routledge, 2004).

Lazzarato, Maurizio. 'Immaterial Labour', in Paulo Virno and Michael Hardt (eds). Radical Thought in Italy: A Potential Politics ((Minneapolis: University of Minnesota Press, 1996), 133-147.

Leonardi, Paul M. 'Digital Materiality? How Artifacts Without Matter, Matter', First Monday 15.6 (2010) http://firstmonday.org/article/view/3036/2567

Lepore, Jill. 'The Disruption Machine: What the Gospel of Innovation Gets Wrong', The New Yorker, June 23 (2014), http://www.newyorker.com/magazine/2014/06/23/the-disruptionmachine

Lobenstine, Lori and Kenneth Bailey. 'Redlining the Adjacent Possible: Youth and Communities of Color Face the (Not) New Future of (Not) Work', Future of Work Project (Open Society Foundations, 2014).

McDonough, William and Michael Braungart. Cradle to Cradle: Remaking the Way We Make Things (New York: North Point Press, 2002).

McPherson, Tara. 'A Rule Set for the Future', in Tara McPherson (ed.). Digital Youth, Innovation, and the Unexpected (Cambridge, MA: MIT Press, 2008), 1-26.

Mouffe, Chantal. 'Pluralism, Dissensus and Democratic Citizenship', II Seminário Internacional Educação Intercultural, Gênero e Movimentos Sociais. Identidade, Diferença, Mediações (2003): 1-10.

Nissenbaum, Helen. 'How Computer Systems Embody Values', Computer 34.3 (2001): 117-119.

Norman, Donald A. The Design of Everyday Things (New York: Doubleday 1990).

Orlikowski, Wanda J. 'Sociomaterial Practices: Exploring Technology at Work', Organisation Studies 28.9 (2007): 1435-1448.

Parikka, Jussi. 'New Materialism as Media Theory: Medianatures and Dirty Matter', Communication and Critical/Cultural Studies 9.1 (2012): 95-100.

Pinch, Trevor J. and Wiebe E. Bijker. 'The Social Construction of Facts and Artefacts: Or How the Sociology of Science and the Sociology of Technology Might Benefit Each Other', Social Studies of Science 14.3 (1984): 399-441.

Tsing, Anna Lowenhaupt. Friction: An Ethnography of Global Connection (Princeton, NJ: Princeton University Press, 2005).

Rheingold, Howard. 'Using Participatory Media and Public Voice to Encourage Civic Engagement', in W. Lance Bennet (ed.). Civic Life Online: Learning How Digital Media Can Engage Youth (Cambridge, Mass: MIT Press 2008): 97-118.

Rise of the Robots. The Economist, 29 March (2014), http://www.economist.com/printedition/2014-03-29 
Robles, Erica and Mikael Wiberg. 'From Materials to Materiality: Thinking of Computation from Within an Icehotel', Interactions 18.1 (2011): 32-37.

Salehi, Niloufar, Lilly Irani, Ali Al Khatib and Michael Bernstein. 'Dynamo: Designing Interactive Technology to Support Social Movements in Digital Labor', Future of Work Project (Open Society Foundations, 2014).

Scholz, Trebor. Digital Labor: The Internet as Playground and Factory (New York: Routledge, 2012).

Spinuzzi, Clay. 'The Methodology of Participatory Design', Technical Communication 52.2 (2005): 163-174.

Star, Susan Leigh. 'The Ethnography of Infrastructure', American Behavioral Scientist 43.3 (1999): 377-391.

Suchman, Lucy. 'Anthropological Relocations and the Limits of Design', Annual Review of Anthropology 40 (2011): 1-18.

Terranova, Tiziana. 'Free Labor: Producing Culture for the Digital Economy', Social Text 18.2 (2000): 33-58.

Tufekci, Zeynep. 'Failing the Third Machine Age: When Robots Come for Grandma', Medium, July 22 (2014), https://medium.com/message/failing-the-third-machine-age1883 e647ba74

Wynne, Brian. 'Public Engagement as a Means of Restoring Public Trust in Science-Hitting the Notes, but Missing the Music'? Community Genetics 9.3 (2006): 211-220.\#\#\#\# 
The LOCKSS System has the permission to collect, preserve and serve this open access

Archival Unit

\section{OPEN HUMANITIES PRESS}

The Fibreculture Journal is published by The Fibreculture Journal Incorporated in partnership with Open Humanities Press. 